\title{
Durability of Mortars Packaged with Production Waste of Autoclaved Aerated Concrete
}

\author{
Maurizio Nicolella ${ }^{1}$, Claudio Scognamillo ${ }^{2}$ and Federica Vitale ${ }^{3}$ \\ 1 Department of Civil, Architectural and Environmental Engineering (DICEA), University of \\ Naples Federico II, 80125-Naples, Italy, maurizio.nicolella@unina.it \\ ${ }^{2}$ Department of Civil, Architectural and Environmental Engineering (DICEA), University of Naples \\ Federico II, 80125-Naples, Italy, claudio.scognamillo@unina.it \\ ${ }^{3}$ Department of Civil, Architectural and Environmental Engineering (DICEA), University of Naples \\ Federico II, 80125-Naples, Italy, federica.vitale@unina.it
}

\begin{abstract}
The building sector is responsible for the introduction of about $40 \%$ of the waste in the environment (60 Mtons per year in Italy), with serious consequences for our future. Therefore, the statistics of the last few years have induced many researchers and many companies to investigate more sustainable products and technologies. Among these strategies, the re-use of waste materials has been widely encouraged. Many solutions have been proposed in the field of mortars for which the use of waste products such as ceramic materials, polystyrene, clay, concrete, has been tried out. The results have often been encouraging, especially for masonry mortars. Nevertheless, very few attempts have been made to place this type of products on the market. Moreover, the "younger" building materials such as Autoclaved Aerated Concrete have not been fully investigated in their potential use as recycled aggregates. The goal of this research was to evaluate the characteristics of mortars packaged with different percentages of production waste of Autoclaved Aerated Concrete components as aggregates, in order to assess the possible use of these conglomerates as masonry mortars or as plasters. The first campaign included tests for determining mechanical resistance, density, capillary water absorption, adherence to substrate, resistance to carbonation. The tested mortars had satisfactory mechanical characteristics and generally exhibited a good capacity to withstand the actions of atmospheric agents. Finally, the results highlighted the direct connection between Autoclaved Aerated Concrete percentage and mechanical and durability properties.
\end{abstract}

Keywords: Building Materials Production Waste, Carbonation, Lightweight Aggregates, Recycled Conglomerates, Sustainability.

\section{Introduction}

The reuse of building waste materials in sustainable concretes or mortars has raised over the last years due to the environmental impact of building constructions. Building materials production waste is preferred rather than Construction and Demolition one due to its controlled chemical composition. The replacement of ordinary aggregates with production waste ones generally affects the mechanical performances of concretes or mortars owing to the low density of recycled aggregates (de Brito et al., 2005; Ćosić et al., 2015).

Nepomuceno, Isidoro and Catarino (2018) suggested a 30\% threshold value of volumereplacement percentage of natural coarse aggregate with recycled ceramic in case of structural concrete. Actually, an increase of porosity and of average pore diameter is observed when the recycled aggregates are used (Anastasiou et al.,2018; Dang et al., 2019). The accretion of 
macropores and the reduction of micropores increases the resistance to external sulphate attack as a consequence of the lower capillary pores transport phenomena (Coppola et al., 2018). Moreover, the porosity improves the thermal insulation performances of mortars (Khan, 2002; Mendes et al., 2019).

Despite the raising interest on recycled lightweight aggregates, it is presently unclear whether the high porous structure of the recycled conglomerates affects their durability due to the microstructural changes induced by the aggregates. In particular, the relation between recycled mortars morphology and their carbonation resistance has not been fully investigated.

In order to analyze the effects of the use of a production waste lightweight material on the physical, the mechanical and the resistance to carbonation properties of conglomerates, five groups of mortars packaged with an increasing percentage by mass of Autoclaved Aerated Concrete (AAC) recycled aggregates were tested and compared. The changes in density, porosity, water adsorption, mechanical strengths and carbonation depths were measured.

The results of this study may be used to define the threshold of AAC aggregate percentage with the respect to the application of conglomerate as masonry mortars or as renderings and plasters.

\section{Materials and Methods}

\subsection{Materials}

The tested mortars were packaged with natural hydraulic lime (NHL 5 according to UNI EN 459-1:2010 standard) sul (2010

A natural siliceous aggregates. The natural the manufacturer, was 1460 resulted from the produ
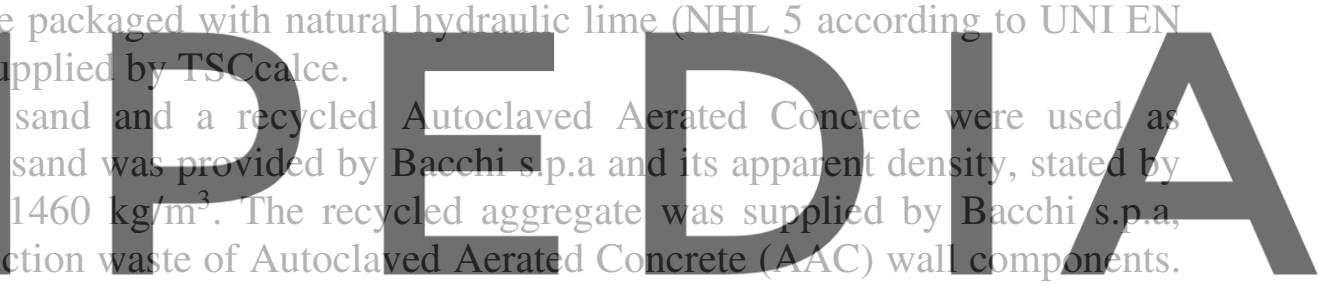

The particles size distribution of the recycled aggregate was measured through the dry sieving

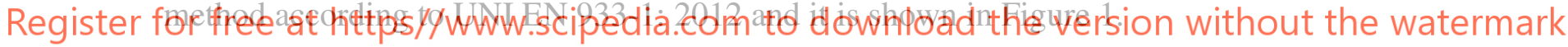

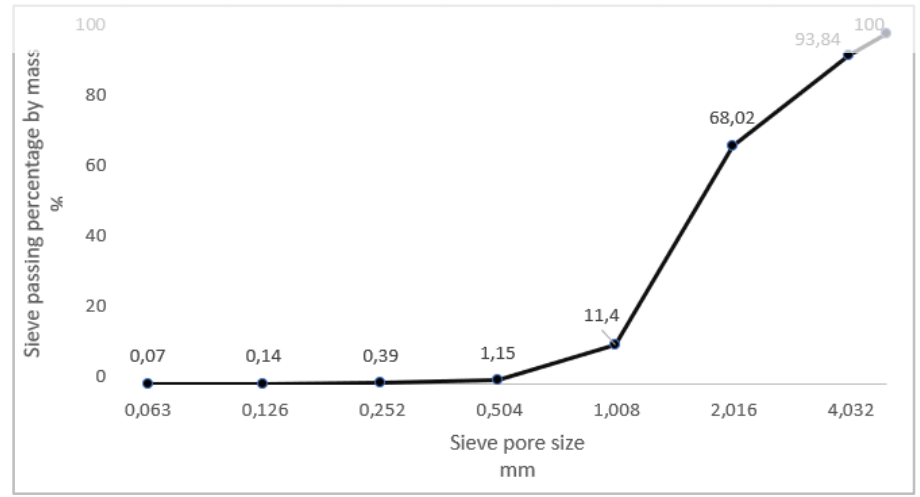

Figure 1. Particle size distribution of Autoclaved Aerated Concrete recycled aggregates according to the sieving test method.

The particle density and the water adsorption of AAC aggregates were analyzed according to UNI EN 1097-6:2013 pycnometer method for aggregate particles passing $4 \mathrm{~mm}$ test sieve and retained on the $0,063 \mathrm{~mm}$ test sieve. The outcomes are shown in Table 1. 
Table 1. Particle density and water adsorption of Autoclaved Aerated Comcrete recycled aggregates.

\begin{tabular}{cccccccc}
\hline $\begin{array}{c}\mathrm{M} 1 \\
(\mathrm{~g})\end{array}$ & $\begin{array}{c}\mathrm{M} 2 \\
(\mathrm{~g})\end{array}$ & $\begin{array}{c}\text { M3 } \\
(\mathrm{g})\end{array}$ & $\begin{array}{c}\text { M4 } \\
(\mathrm{g})\end{array}$ & $\begin{array}{c}\rho_{\mathrm{rd}} \\
\left(\mathrm{kg} / \mathrm{m}^{3}\right)\end{array}$ & $\begin{array}{c}\rho_{\text {ssd }} \\
\left(\mathrm{kg} / \mathrm{m}^{3}\right)\end{array}$ & $\begin{array}{c}\rho_{\mathrm{a}} \\
\left(\mathrm{kg} / \mathrm{m}^{3}\right)\end{array}$ & $\begin{array}{c}\mathrm{W} \\
(\%)\end{array}$ \\
\hline 77,93 & 477,73 & 452,29 & 45,11 & 860 & 1480 & 2290 & 72,76 \\
\hline
\end{tabular}

M1, saturated and surface dried mass in air; M2, mass of pycnometer containing the saturated aggregate sample and the water; M3, mass of pycnometer filled with water only; $\rho_{\text {rd }}$, oven dried particle density; $\rho_{\text {ssd }}$, saturated and surface dried particle density; $\rho_{\mathrm{a}}$, apparent particle density; $\mathrm{W}$, water adsorption.

The chemical composition of the recycled aggregates was determined by a ThermoGravimetric Analysis (TGA) using a Netzsch- STA 409 PC Luxx apparatus. The mass losses of an AAC aggregate sample of $20 \mathrm{mg}$ were monitored over time as the sample was heated in a controlled atmosphere. The temperature ranged from $23^{\circ}$ to $1200^{\circ}$ with a $10^{\circ} / \mathrm{min}$ heating rate. The mineralogical composition of AAC aggregates was analyzed by X-ray Diffraction (XRD) technique using a Philips X'pert PRO multipurpose powder diffractometer with X-ray wavelength of $1,54 \AA$. The outcomes were compared with the standard patterns of the International Centre for Diffraction Data database. The main mineralogical phases were Silicon Oxide, Calcium Carbonate, Calcium Hydroxide Hydrated Silicates and Calcium Sulfate Hydrated. A distilled water was used as kneading water.

Five groups of mortars with five specimens in each group were analyzed. All the tested specimens were packaged using the hydraulic lime and a binder-aggregate ratio of $1: 3$ by mass.
The first group - noted 1 - was taken as reference and it was composed of mortars with $100 \%$
natural aggregate percentage. In the other four groups - noted 2,3,4,5 - the natural sand.was
gradually replaced with an increasing percentage by mass of recycled aggregate from $12,5 \%$ to
$50 \%$. The water - binder ratio of 2,3,4,5 was adjusted due to A AC aggregate water adsorption. Table 2 shows the compositions of the tested mortars.

Register for free at https//www.scipedia.com to download the version without the watermark

\begin{tabular}{ccccccc}
\hline & $\mathrm{HL}(\mathrm{g})$ & $\mathrm{SS}(\mathrm{g})$ & $\mathrm{AAC}(\mathrm{g})$ & $\mathrm{W}(\mathrm{g})$ & $\mathrm{W} / \mathrm{B}$ & $\mathrm{RA}(\%)$ \\
\hline 1 & 450 & 1350 & 0 & 225 & 0,50 & 0 \\
\hline 2 & 450 & 1181,25 & 168,75 & 337,5 & 0,75 & 12,5 \\
\hline 3 & 450 & 1012,50 & 337,50 & 450 & 1,00 & 25 \\
\hline 4 & 450 & 843,75 & 506,25 & 562,5 & 1,25 & 37,5 \\
\hline 5 & 450 & 675 & 675 & 675 & 1,50 & 50 \\
\hline
\end{tabular}

HL, hydraulic lime; SS, siliceous sand; AAC, Autoclaved Aerated Concrete recycled aggregates; $\mathrm{W}$, kneading water; W/B, water/binder ratio; RA, AAC percentage by mass on the total aggregates.

\subsection{Methods}

\subsubsection{Mixing procedure of mortars and testing program of physical, mechanical and resistance to carbonation properties}

Physical, mechanical and resistance to carbonation tests were performed on prismatic specimens according to UNI EN 196-1:1996 specifications. The natural sand and the recycled 
aggregates were dry premixed before they were blended with the hydraulic lime and the kneading water. The specimens were molded in prismatic casts $(40 \times 40 \times 160 \mathrm{~mm})$ and cured in a climatic chamber (MSL Humichamber EC 125) under controlled conditions according to UNI EN 1015-11:2007. Three specimens of each group were tested for density, porosity, water adsorption, compressive and flexural strength, two specimens of each group were tested for resistance to carbonation.

\subsubsection{Apparent and bulk dry densities, open porosity and water adsorption}

The tests were conducted according to UNI EN 1936:2007 specifications. The prismatic specimens were dried in an oven at $70 \pm 5^{\circ}$ temperature until a constant mass was recorded.

As the mass was stabilized, the three specimens of each group were weighted and their dry mass M1 was recorded. Then the dry specimens were stored for $24 \mathrm{~h}$ under vacuum in a vessel in which the pression was gradually lowered to $15 \pm 5 \mathrm{mmHg}$. After this period a volume of water was introduced in the vessel so that the specimens were immersed for at least $5 \mathrm{~mm}$. The specimens were kept under vacuum and immersed in water for $24 \mathrm{~h}$ with the same pression of $15 \pm 5 \mathrm{mmHg}$. Finally, the pression was returned to the atmospheric value and the specimens were left immersed for other $24 \mathrm{~h}$. After the $72 \mathrm{~h}$ storage the immersed specimens were weighted and the M2 value was recorded. The mortars were then wiped with a cloth and the mass of the saturated specimens, noted M3, was measured.

\section{The apparent $\left(\rho_{a}\right)$ and the bulk $\left(\rho_{r}\right)$ densities, the open porosity $(p)$ and the water adsorption}

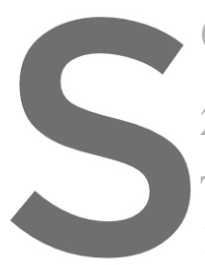

\section{(W) were finally calculate}

2.3 Mechanical Properties

The compressive and the flex

1:2007 procedure using the
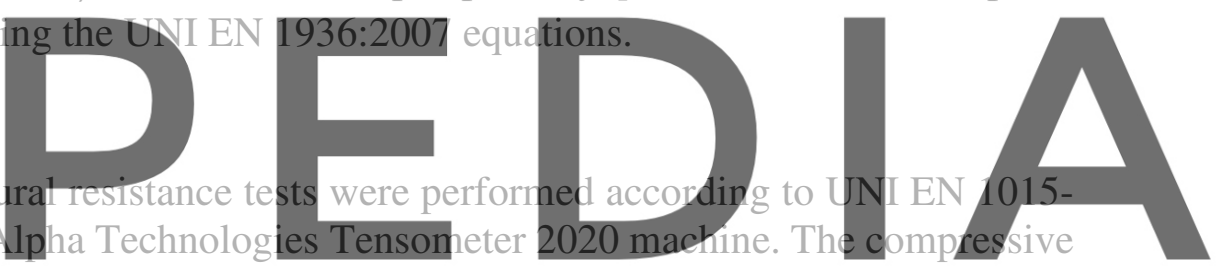

load cells were of three types: groups 3,4,5 were tested with $5 \mathrm{kN}$, group 2 with $10 \mathrm{kN}$ and group

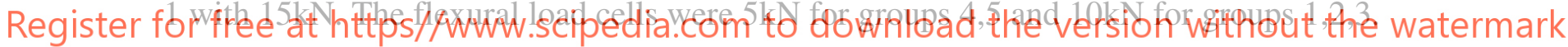

\subsubsection{Adherence on substrates test}

The adhesive strength of mortars on substrates was measured according to UNI EN 101512:2016 procedures. Three different substrates - brick, tuff and lapil-cement - were tested and their fracture patterns were compared.

\subsubsection{Resistance to carbonation}

The resistance to carbonation test and the analysis of the results were conducted according to UNI EN 13295:2005 indications. The carbonation depth was measured according to UNI EN 14630:2003 procedures. The measurement was repeated only two times - on $15^{\text {th }}$ and on $30^{\text {th }}$ day- because all the specimens were fully carbonated after thirty days.

\section{Results}

\subsection{Apparent and Bulk Dry Densities, Open Porosity and Water Adsorption}

The apparent and the bulk dry densities, the open porosity and the water adsorption of the tested 
mortars are shown in Table 3. The mean values for the three specimens of each group are reported. The reference mortar -1- exhibited an apparent density 66\% higher than the group 5.

The open porosity and the water adsorption of group 5 were respectively twice and three times as high as group 1.

Table 3. Apparent and bulk dry densities, open porosity and water adsorption. Mean values of the three specimens of each group are reported.

\begin{tabular}{ccccc}
\hline & $\rho_{\mathrm{a}}\left(\mathrm{g} / \mathrm{cm}^{3}\right)$ & $\rho_{\mathrm{r}}\left(\mathrm{g} / \mathrm{cm}^{3}\right)$ & $p(\%)$ & $W(\%)$ \\
\hline 1 & 1,75 & 2,24 & 22 & 12,58 \\
\hline 2 & 1,51 & 2,13 & 29 & 19,35 \\
\hline 3 & 1,27 & 1,95 & 35 & 27,12 \\
\hline 4 & 1,20 & 1,91 & 37 & 31,07 \\
\hline 5 & 1,05 & 1,87 & 44 & 41,53 \\
\hline
\end{tabular}

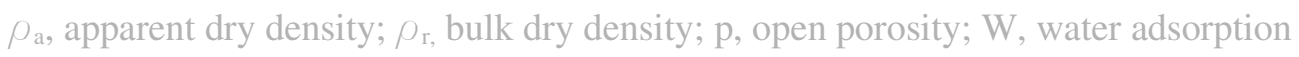

\subsection{Mechanical Properties}

The mean values of flexural and compressive strength are reported in Table 4. The flexural resistance of group 4 was tested only on two specimens due to the breakage of one sample during the curing period. The group 5 exhibited a flexural and a compressive resistance fifteen and ten times, respectively, as low as mortars of group
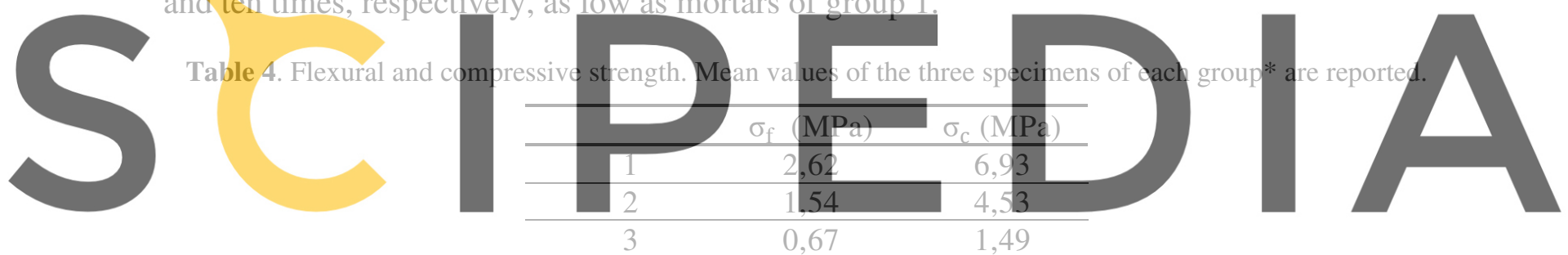

Register for free at https//www.scipedia.com to.dBownload the version without the watermark

Except for flexural resistance of group 4 (mean values of two specimens); $\sigma_{f}$, flexural resistance; $\sigma_{c}$, compressive resistance.

The compressive strength values were compared to UNI EN 998-2:2016 and to UNI EN 998-1:2016 specifications with respect to the classes of masonry and rendering or plastering mortars, respectively. The classification of the tested mortars is reported in Table 5.

\subsection{Adherence on Substrates Test}

The adhesive strength of mortars on each of the tested substrates is shown in Table 6. Mean values of recorded resistance are reported along with UNI EN 1015-12:2016 fracture pattern classification. The A, B, C pattern types referred to an adhesion fracture at the interface between mortar and substrate, to a cohesion fracture in the mortar itself and to a cohesion fracture in the substrate material, respectively. 
Table 5. Classification of the tested mortars according to UNI EN 998-1,2:2016.

\begin{tabular}{cccc}
\hline & UNI EN 998-2 & \multicolumn{2}{c}{ UNI EN 998-1 } \\
& Table 1 & Table 1 & Table 2 \\
1 & M5 & CS III/ IV & GP-LW-CR-OC \\
\hline 2 & M2,5 & CS II/ III & GP-LW-CR-OC-R-T \\
\hline 3 & M1 & CS I & GP-LW-CR-OC-T \\
\hline 4 & $/$ & CS I & GP-LW-CR-OC-T \\
\hline 5 & $/$ & CS I & GP-LW-CR-OC-T \\
\hline
\end{tabular}

/ not classified; GP general purpose; LW lightweight rendering/plastering; CR coloured rendering mortar; OC one coat rendering mortar for external use; $\mathrm{R}$ renovation mortar; $\mathrm{T}$ thermal insulation mortar

Table 6. Adhesive strength on substrates. Mean values of resistance and fracture pattern type are reported.

\begin{tabular}{ccccccc}
\hline & \multicolumn{2}{c}{ Brick } & \multicolumn{2}{c}{ Tuff } & \multicolumn{2}{c}{ Lapil-cement } \\
\cline { 2 - 7 } & $\mathrm{f}_{\mathrm{u}}(\mathrm{MPa})$ & $\mathrm{FP}$ & $\mathrm{f}_{\mathrm{u}}(\mathrm{MPa})$ & $\mathrm{FP}$ & $\mathrm{f}_{\mathrm{u}}(\mathrm{MPa})$ & FP \\
\hline 1 & 0,24 & $\mathrm{~A}$ & 0,29 & $\mathrm{~B} / \mathrm{C}$ & 0,56 & $\mathrm{~A}$ \\
\hline 2 & 0,34 & $\mathrm{~A}$ & 0,34 & $\mathrm{~B} / \mathrm{C}$ & 0,26 & $\mathrm{~B}$ \\
\hline 3 & 0,30 & $\mathrm{~B}$ & 0,04 & $\mathrm{~B} / \mathrm{C}$ & 0,14 & $\mathrm{~B}$ \\
\hline 4 & 0,16 & $\mathrm{~B}$ & 0,05 & $\mathrm{~A}$ & 0,12 & $\mathrm{~B}$ \\
\hline 5 & $/$ & $/$ & $/$ & $/$ & 0,09 & $\mathrm{~B}$ \\
\hline
\end{tabular}

$\mathrm{f}_{\mathrm{u}}$, adhesive strength; FP, fracture pattern; / it was not possible to measure the strength
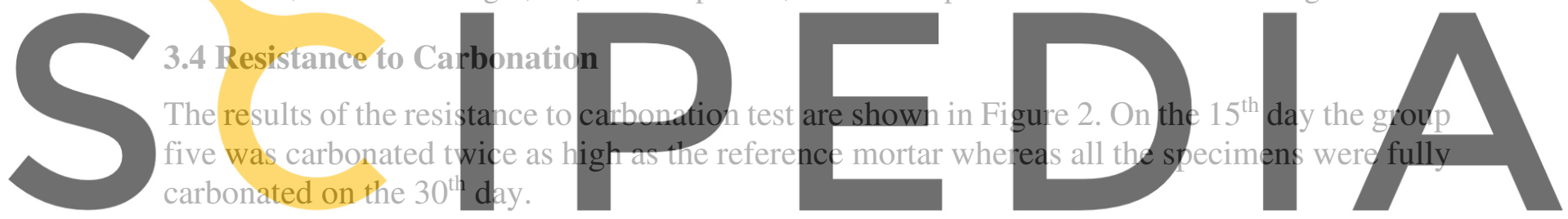

Register for free at https//www.scipedia.com to download the version without the watermark

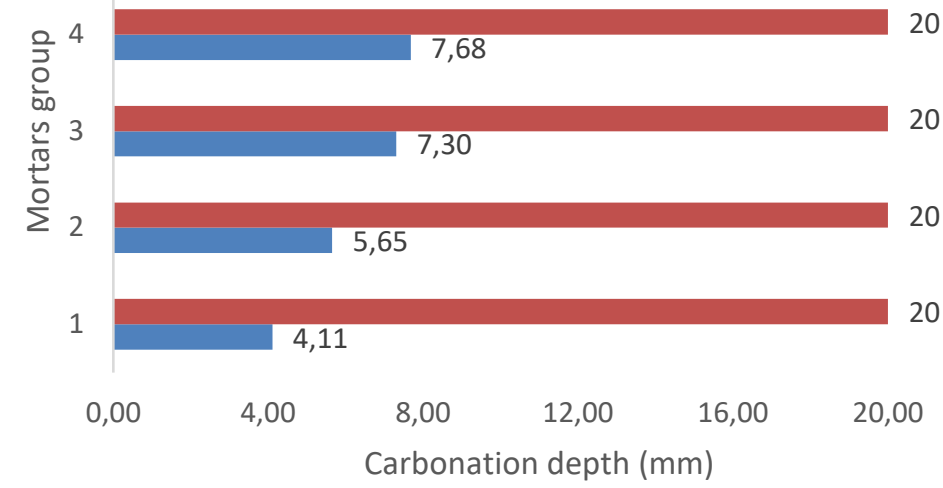

after 30 days

after 15 days

Figure 2. Resistance to carbonation test. Carbonation depth on 15 th and 30th day are reported. 


\section{Discussions and Conclusions}

The aim of the research was to investigate the influence of Autoclaved Aerated Concrete waste production aggregates on the mechanical and the durability properties of mortars, with specific respect to the resistance to carbonation. Results indicate that the replacement of the ordinary siliceous sand with AAC aggregate impacts on the hard-state properties of mortars.

The density and the mechanical properties - compressive and flexural strengths - and the adhesive strength to substrates decreased as the recycled aggregate percentage grew. Concerning the adhesive strength to substrate, the adherence to tuff rapidly lowered as the sand was replaced with AAC. Moreover, the open porosity and the water adsorption increased as AAC replaced the natural sand. Actually, the mortars with a higher percentage of AAC needed more kneading water due to the AAC adsorptive properties. Finally, the highest AAC mortar exhibited a short-term low resistance to carbonation, whereas the same value of carbonation depth was observed on $30^{\text {th }}$ day measurement for all the specimens.

Similar trends were reported by Blanco et al. (2000) who recorded a strong correlation between the use of lightweight aggregates and the physical and the mechanical properties of concretes. Moreover, the discussed results are consistent with Zhao et al. (2015) who measured the reduction of flexural and compressive strength of concretes due to the use of recycled aggregates. Tewar et al. (2017) also investigated the substitution of natural sand with AAC waste production aggregates and they reported the growing of kneading water mass and the lowering of compressive strength as AAC percentage was kept higher. Finally, the higher

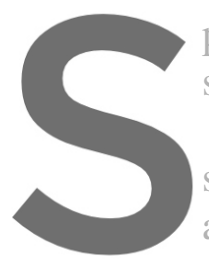
porosity of recycled-aggregates conglonserates
similar to Evangelista et al.,(2010); de Oliveir
However, the tested mortarts were packaged
sizes distribution of aggregates, mainly ranged
are necessary to find if the type of binder a
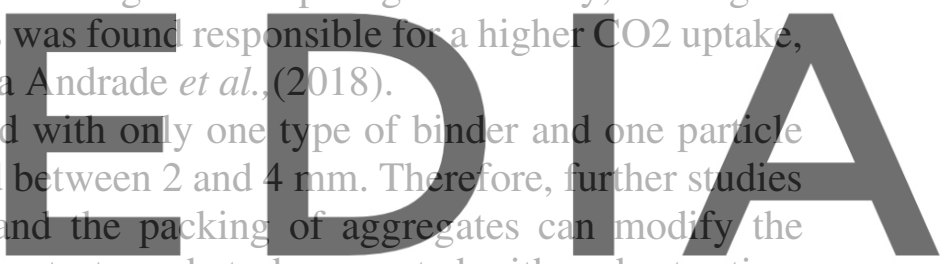

discussed results. The resistance to carbonation test needs to be repeated with a shorter time

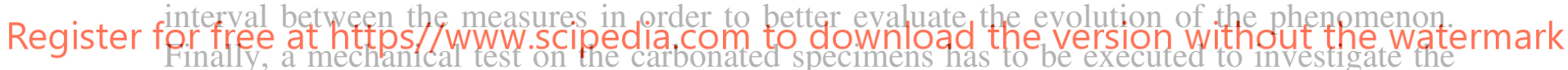
effects of CO2 diffusion on the compressive and the flexural strength of the mortars.

In conclusions, the substitution of natural sand with AAC aggregates seems to be useful to package both masonry and rendering or plastering mortars. Moreover, the increased porosity and the reduced density of higher AAC percentage mortars suggest their potential thermal insulating properties. Conversely, a threshold for AAC percentage is necessary for masonry mortars packaged with hydraulic lime due to the reduction of mechanical performances and resistance to carbonation.

\section{ORCID}

Maurizio Nicolella: http://orcid.org/0000-0002-7140-6759

Claudio Scognamillo: https://orcid.org/0000-0002-0954-7323

Federica Vitale: https://orcid.org/0000-0003-4297-3372

\section{References}

Anastasiou, E., Papachristoforou, M., Anesiadis, D., Zafeiridis, K. and Tsardaka, E. C. (2018). Investigation of the use of recycled concrete aggregates originating from a single ready-mix concrete plant. Applied Sciences (Switzerland), 8(11). https://doi.org/10.3390/app8112149 
Blanco, F., Garciéa, P., Mateos, P. and Ayala, J. (2000). Characteristics and properties of lightweight concrete manufactured with cenospheres. Cement and Concrete Research, 30(11), 1715-1722. https://doi.org/10.1016/S0008-8846(00)00357-4

Coppola, B., Courard, L., Michel, F., Incarnato, L., Scarfato, P. and Di Maio, L. (2018). Hygro-thermal and durability properties of a lightweight mortar made with foamed plastic waste aggregates. Construction and Building Materials, 170, 200-206. https://doi.org/10.1016/j.conbuildmat.2018.03.083

Ćosić, K., Korat, L., Ducman, V. and Netinger, I. (2015). Influence of aggregate type and size on properties of pervious concrete. Construction and Building Materials, $78, \quad 69-76$. https://doi.org/10.1016/j.conbuildmat.2014.12.073

Dang, J. and Zhao, J. (2019). Influence of waste clay bricks as fine aggregate on the mechanical and microstructural properties of concrete. Construction and Building Materials, 228, 116757. https://doi.org/10.1016/j.conbuildmat.2019.116757

de Oliveira Andrade, J. J., Possan, E., Squiavon, J. Z. and Ortolan, T. L. P. (2018). Evaluation of mechanical properties and carbonation of mortars produced with construction and demolition waste. Construction and Building Materials, 161, 70-83. https://doi.org/10.1016/j.conbuildmat.2017.11.089

Evangelista, L. and de Brito, J. (2010). Durability performance of concrete made with fine recycled concrete aggregates. Cement and Concrete Composites, 32(1), 9-14. https://doi.org/10.1016/j.cemconcomp.2009.09.005

M.I. Khan. (2002). Factors affecting the thermal properties of concrete and applicability of its prediction models. Building and Environment, 37, 607-614.

Mendes, J. C., Barreto, R. R., de Paula, A. C. B., Elói, F. P. da F., Brigolini, G. J. and Peixoto, R. A. F. (2019). On the relationship between morphology and thermal conductivity of cement-based composites. Cement and Concrete Composites, 104(October 2018), 103365. https://doi.org/10.1016/j.cemconcomp.2019.103365

Nepomuceno, M. C. S., Isidoro, R. A. S. and Catarino, J. P. G. (2018). Mechanical performance evaluation of concrete made with recycled ceramic coarse aggregates from industrial brick waste. Construction and Building Materials, 165, 284-294.

Tewar, B., Shah, P. M. Manufactured AAC https://doi.org/10.1016/j.1 properties
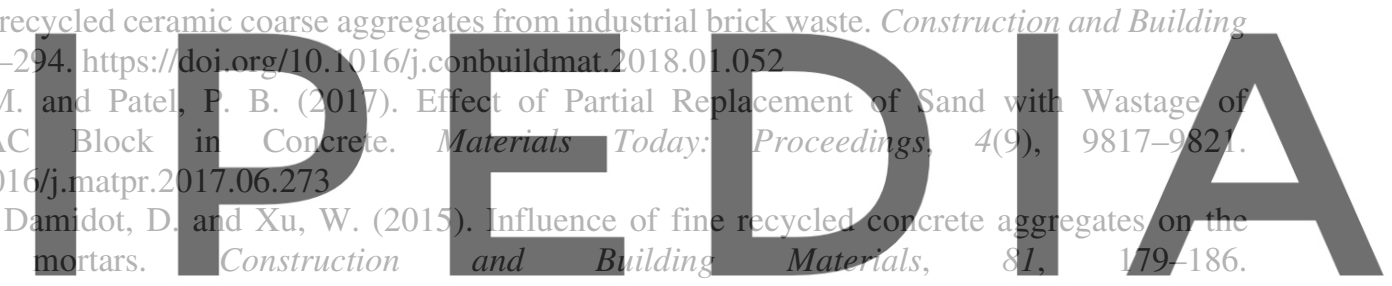

https://doi.org/10.1016/j.conbuildmat.2015.02.037

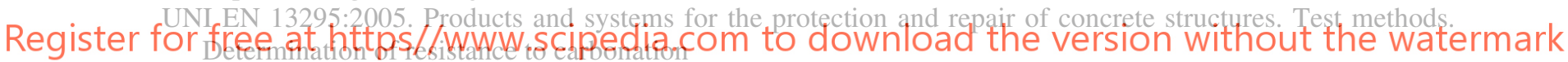

UNI EN 1015-11:2007. Determination of flexural and compressive strength of hardened mortars

UNI EN 1936:2007. Determination of real density and apparent density, and of total and open porosity

UNI EN 14630:2007. Products and systems for the protection and repair of concrete structures. Test methods. Determination of carbonation depth in hardened concrete by the phenolphthalein method

UNI EN 196-6:2010. Methods of testing cement - Part 6: Determination of fineness.

UNI EN 459-1:2010. Building lime - Part 1. Definitions, specifications and conformity criteria

UNI EN 933-1:2012. Tests for geometrical properties of aggregates - Part 1: Determination of particle size distribution - sieving method

UNI EN 1097-6:2013. Tests for mechanical and physical properties of aggregates - Part 6: Determination of particle density and water absorption

UNI EN 998-1:2016. Specification for mortar for masonry - Part 1: Rendering and plastering mortars

UNI EN 998-2:2016. Specification for mortar for masonry - Part 2: Masonry mortar

UNI EN 1015-12:2016. Methods of test for mortar of masonry - Part 12: Determination of adhesive strength of hardened rendering and plastering mortars on substrates. 